\title{
Economic evaluation of brief sex counselling for sexually dysfunctional adolescents
}

Citation for published version (APA):

Grauvogl, A., Peters, M. L., Evers, S. M. A. A., \& van Lankveld, J. J. D. M. (2015). Economic evaluation of brief sex counselling for sexually dysfunctional adolescents. International Journal of Sexual Health, 27(4), 469-484. https://doi.org/10.1080/19317611.2015.1052176

Document status and date:

Published: 02/10/2015

DOI:

10.1080/19317611.2015.1052176

Document Version:

Publisher's PDF, also known as Version of record

Document license:

Taverne

Please check the document version of this publication:

- A submitted manuscript is the version of the article upon submission and before peer-review. There can be important differences between the submitted version and the official published version of record.

People interested in the research are advised to contact the author for the final version of the publication, or visit the DOI to the publisher's website.

- The final author version and the galley proof are versions of the publication after peer review.

- The final published version features the final layout of the paper including the volume, issue and page numbers.

Link to publication

\footnotetext{
General rights rights.

- You may freely distribute the URL identifying the publication in the public portal. please follow below link for the End User Agreement:

www.umlib.nl/taverne-license

Take down policy

If you believe that this document breaches copyright please contact us at:

repository@maastrichtuniversity.nl

providing details and we will investigate your claim.
}

Copyright and moral rights for the publications made accessible in the public portal are retained by the authors and/or other copyright owners and it is a condition of accessing publications that users recognise and abide by the legal requirements associated with these

- Users may download and print one copy of any publication from the public portal for the purpose of private study or research.

- You may not further distribute the material or use it for any profit-making activity or commercial gain

If the publication is distributed under the terms of Article $25 \mathrm{fa}$ of the Dutch Copyright Act, indicated by the "Taverne" license above, 


\section{Economic evaluation of brief sex counseling for sexually dysfunctional adolescents}

Andrea Grauvogl, Madelon L. Peters, Silvia M. A. A. Evers \& Jacques J. D. M. van Lankveld

To cite this article: Andrea Grauvogl, Madelon L. Peters, Silvia M. A. A. Evers \& Jacques J. D. M. van Lankveld (2015) Economic evaluation of brief sex counseling for sexually dysfunctional adolescents, International Journal of Sexual Health, 27:4, 469-484, DOI: 10.1080/19317611.2015.1052176

To link to this article: https://doi.org/10.1080/19317611.2015.1052176

曲 Published online: 13 Nov 2015.

Submit your article to this journal ¿

Џll Article views: 167

Q View related articles $\sqsubset$

View Crossmark data ¿

Citing articles: 1 View citing articles 5 


\title{
ECONOMIC EVALUATION OF BRIEF SEX COUNSELING FOR SEXUALLY DYSFUNCTIONAL ADOLESCENTS
}

\author{
Andrea Grauvogl ${ }^{1}$, Madelon L. Peters ${ }^{1}$, Silvia M. A. A. Evers ${ }^{2}$, Jacques J. D. M. van Lankveld ${ }^{3}$ \\ ${ }^{1}$ Faculty of Psychology and Neuroscience, Department of Clinical Psychological Science, Maastricht \\ University, Maastricht, The Netherlands \\ ${ }^{2}$ Faculty of Health, Medicine, and Life Sciences, Caphri School of Public Health and Primary Care, \\ Department of Health Services Research, Maastricht University, Maastricht, The Netherlands \\ ${ }^{3}$ Faculty of Psychology, Open University of the Netherlands, Heerlen, The Netherlands
}

\begin{abstract}
Objectives: In a randomized controlled trial brief sex counselling (BSC), intensive sexual healthcare (ISH) and no treatment (NT) for adolescents with a sexual dysfunction were compared. The aim of this study was to assess the cost-effectiveness and cost-utility of BSC versus ISH and NT from a societal perspective. Methods: Costs, sexual functioning and quality of life were measured during 6 months. Primary outcome measures were measured with the Female Sexual Functional Index, the International Index of Erectile Function and the utilities reflecting Quality of Life based on the SF-36. Uncertainty was dealt with by using bootstrap replications and sensitivity analyses. Results: Results show that the societal costs were the highest for ISH followed by NT and BSC. The difference in costs between ISH compared to NT and BSC was significant. Furthermore, there were no significant group differences in sexual functioning or quality of life. With respect to the cost-effectiveness and cost-utility, BSC can be considered to be a suitable treatment for adolescents with a sexual dysfunction. Conclusions: Due to the lack of a significant difference in clinical effect, it can be concluded that BSC is the cheapest treatment option when implementing the intention-to-treat, besides a no treatment option, for adolescents with a sexual dysfunction.
\end{abstract}

KEYWORDS. Sexual dysfunction, adolescents and young adults, psychological treatment, costeffectiveness

\section{INTRODUCTION}

Although Dutch adolescents are considered to be sexually healthy (Bakker \& Vanwesenbeeck, 2006), Kedde (2012) reported that substantial numbers of adolescents in The Netherlands experience problems with sexual desire, sexual arousal, orgasm, and pain during sexual encounters. Female adolescents especially report these problems. Among girls, 43.4\% experience at least one sexual dysfunction. Orgasmic disorders are the most frequently reported sexual dysfunction (20.3\%). Among boys, 27.3\% experience at least one sexual dysfunction. Premature ejaculation is the most frequently reported sexual dysfunction $(12.6 \%)$. These findings can be taken to imply that sexual function problems in adolescents warrant the attention of researchers, professionals, and policymakers.

When adolescents acknowledge that they experience a sexual problem, finding and receiving adequate care is often problematic. The loss of anonymity, financial costs of intensive sexual health care (ISH), and limited familiarity with and lack of confidence in the health care services available can be problems (Akre, Michaud, \& Suris, 2010; Bakker et al., 2009; Bakker \& Vanwesenbeeck, 2006). Goldmeier, Malik, and Green (2004) calculated that the average cost for treatment delivered by a sex therapist in the United Kingdom is approximately $€ 900(\$ 1,200)$. Given these costs, it is

Received 8 January 2015; revised 20 March 2015; accepted 13 May 2015.

Address correspondence to Andrea Grauvogl, Faculty of Psychology and Neuroscience, Department of Clinical Psychological Science, Maastricht University, P. O. Box 616, 6200 MD Maastricht, The Netherlands. E-mail: Andrea.Grauvogl@maastrichtuniversity.nl 
essential from a societal perspective that cost-effective treatment options are developed and evaluated. There are indications that this is possible for the treatment of sexual dysfunctions. For instance, $14 \%$ of the patients treated in outpatient clinics for sexology and $24 \%$ of the patients treated in mental health care centers could be adequately treated with a less costly, low-threshold intervention (Bakker \& Vanwesenbeeck, 2006; Vroege, Lotgerink, van der Rhee, Tanis-Nauta, \& Weijmar Schultz, 2007). However, the cost-effectiveness of these low-threshold interventions needs to be examined first to obtain the required financial support. There are published economic evaluations concerning HIV care showing that brief behavioral interventions to reduce the incidence of HIV and other sexually transmitted infections are cost-effective (Burgos et al., 2010; Zaric, Bayoumi, Brandeau, \& Owens, 1998). However, to our knowledge, full economic evaluations concerning treatment options for adolescents who experience sexual dysfunctions are lacking.

In this study, we focus on "brief sex counseling." Brief sex counseling (BSC) is a new treatment, developed by the Rotterdam-Rijnmond Public Health Service (PHS) and Maastricht University in The Netherlands, that could provide a more cost-effective treatment for adolescents with sexual dysfunctions.

In a randomized controlled trial, we examined the cost-effectiveness and the cost utility of BSC compared to ISH and no treatment (NT), while focusing on the following research question: Is BSC, compared to ISH and NT, preferable for the treatment of adolescents with sexual dysfunctions in terms of cost-effectiveness from a societal perspective?

\section{METHODS}

\section{Participants}

Participants were included if they met the following criteria: age 18 to 25 years old; at least mild to moderate sexual function problems; no severe psychiatric comorbidity or relational problems; and sexual function problems were not caused by disease, medication/drug use, or physical disabilities (based on a problem history questionnaire). Participants were recruited through referrals from the PHS in RotterdamRijnmond in the Northern parts of The Netherlands, and in Limburg (Southern part of The Netherlands), the Web site Sense, and various other Web sites (http://www.sexcounselling.eu, http://www.sense.info [The webpage is out of business now]). After random assignment, participants received their treatment in one of the following three regions in The Netherlands: Rotterdam, Northern Netherlands, and Limburg.

\section{Procedure}

This economic evaluation was embedded in a trial-based economic evaluation with a time horizon of 6 months. Details of the study are described in the design article (Grauvogl et al., 2009). After informed consent was obtained and participants completed an online screening questionnaire, they were randomly allocated to: (a): BSC, (b) ISH, or (c) NT. The outcomes and costs were measured via a secure Internet link (http://www.emium.nl) before random assignment (during initial screening), at baseline, and at 3 and 6 months after baseline as well as at 9 months after baseline only for $\mathrm{ISH}$ and BSC. To reduce the period that the respondents in the NT group were denied treatment, the last follow-up in this group was at 6 months after baseline. We used a block randomization procedure-and more specifically, an adaptive biased urn randomization for small strata-to ascertain that each intervention runs in equally large groups (Schouten, 1995).

\section{Interventions}

\section{Brief sex counseling}

BSC is a brief, free-of-charge, and lowthreshold treatment for adolescents aged 18 to 25 years old who experience sexual function problems. In a maximum of three sessions, of 45 min each, over a 3-month period, a sex counselor provides treatment. The sex counselor is a nurse who works at Sense and who received supplementary training by a sexologist. The sessions include providing information 
(psychoeducation) and cognitive restructuring. Instructions for home-based exercises, following the principles of the sensate-focus exercises of Masters and Johnson (1970), are also provided during the sessions.

The treatment manual that has been developed for the BSC sessions (Grauvogl \& van Lankveld, 2009) is based on the general principles and practice of sex counseling and on a guideline that was developed for Sense (Ijff, 2006; Leusink \& Nauta, 2009). The manual contains instructions for the sex counselor to address specific sexual problems. In the first session, specific questions regarding sexual functioning and overall sexual history are discussed. Furthermore, an action plan is established to provide an outline of the adolescent's treatment goals and the elements that will be used to alleviate the problem. Several therapeutic techniques are offered in Sessions 2 and 3. During the sessions, the counselor attempts to identify, change, and adjust compromised cognitive processes and deficient coping strategies. Instructions for sensate-focus exercises (Masters \& Johnson, 1970) can be given to help the adolescent (re)discover sexual needs and preferences and to practice sensual and erotic touching, while avoiding performance pressure.

The brief duration of the intervention was expected to render BSC unsuitable to treat individuals with sexual dysfunctions with comorbid relationship and/or psychiatric problems.

\section{Intensive sexual health care}

In the ISH condition, participants received more intensive psychological treatment. During a minimum of six sessions during a 6-month period, a certified sexologist offers sexological treatment based on cognitive-behavioral therapy principles. The sessions are scheduled weekly. Furthermore, in contrast to BSC, the therapist in ISH also addresses the psychological problems of the participant, which may be the cause of the sexual function problem.

\section{No treatment}

The active treatment conditions were compared to the NT condition, which enabled the researchers to control for spontaneous recovery and mere measurement effects. In this condition, participants were requested not to engage in other types of professional help for a 6-month period. After the waiting period, the participants who were allocated to this condition could choose their preferred treatment (BSC or ISH).

\section{Cost Measures and Valuation}

This economic evaluation was performed from a societal perspective, which implies that all relevant costs and outcomes were taken into account. As several countries have a more limited perspective, an additional analysis from a health care perspective was performed. Total costs were estimated using a bottom-up approach, where information on each element of service is multiplied by an appropriate unit cost and is summed to provide an overall total cost (Drummond, Sculpher, Torrance, O'Brien, \& Stoddart, 2005). We assessed intervention costs, health care costs, patient and family costs, and costs in other sectors. For this study, we developed a cost questionnaire for this group based on existing questionnaires (Hakkaart-van Roijen, van Straten, Donker, \& Tiemens, 2002; Koopmanschap et al., 2004), which identified all relevant cost aspects.

To measure the actual use of resources, data were obtained using combined sources (registrations by professionals and the cost questionnaire). Resources used relating to the interventions were based on the registered number of sessions that all professionals spent on the treatment. All use of resources by the adolescent in and outside the healthcare sector was measured by means of the cost questionnaire.

The valuation of health care costs and patient and family costs was based on the updated Dutch manual for cost analysis in health care research (Hakkaart-van Roijen, Tan, \& Bouwmans, 2010). This manual recommends using standardized cost prices. Costs in other sectors, and especially productivity costs, were calculated by means of the friction cost method based on a mean added value of the Dutch working population. The friction cost method takes into account production losses confined 
to the period needed (usually 90 days) to replace a sick employee. Absenteeism from school was calculated using the number of days the adolescents was absent from school. Cost prices are presented in 2012 euro values (Hakkaart-van Roijen et al., 2010).

\section{Outcome Measures}

Several instruments were used to assess the outcomes of the economic evaluation. The primary outcome measures were sexual functioning as measured in women using the Female Sexual Function Index (FSFI; Rosen et al., 2000) and sexual functioning as measured in men using the International Index of Erectile Function (IIEF; Rosen et al., 1997). High scores indicate healthy sexual functioning. To combine female and male sexual functioning data, $Z$ scores were calculated within the female and male subgroups, resulting in average $Z$ score means of 0 , with 1 standard deviation for each participant.

Within the cost-utility analysis, utilities were derived using the Short Form-6D (SF-6D), which is a utility instrument based on the health-related quality-of-life questionnaire Medical Outcomes Study 36-Item Short Form Health Survey (SF-36; Ware \& Sherbourn, 1992). The utility score is derived from 11 items on the SF-36 and is composed of six dimensions of health and was calculated using preferences elicited from a general population in the United Kingdom, the so-called Brazier algorithm (Brazier, Roberts, \& Deverill, 2002). The utility values derived from the Brazier algorithm were used to compute the quality-adjusted life year (QALY) metric by using the area-under-thecurve method (Drummond et al., 2005). The results were a gain of 0.5 QALY because there was a measurement period of only 6 months.

\section{Statistical Methods}

All primary analyses were performed according to the intention-to-treat principle, including data from all participants regardless of whether they completed the measurements or not. Intermittent missing data were imputed by

calculating the mean values of the previous and subsequent time points. Missing data due to lost to follow-up (32\%) were replaced by imputed values, using the last-observation-carried-forward technique. For the analyses, the Statistical Package for the Social Sciences Version 20.0 statistical software and Excel (for the bootstraps) were used.

To describe the cost data, arithmetic means were used. The incremental cost-effectiveness ratio (ICER; Prochaska \& Velicer, 1997) was determined based on the incremental costs and effects of BSC compared with the ISH and NT. The ICER was stated in terms of incremental costs per outcome rate (increase in sexual functioning); the cost-utility ratio focused on the incremental cost per QALY gained.

Group differences in clinical effect (proportion of recovery) and quality of life were analyzed with nonparametric Kruskall-Wallis tests with a $p<.05$ significance level. Because costs were not normally distributed, we performed 5,000 bootstrap simulations.

The economic evaluation included a basecase cost-effectiveness and utility analysis and several sensitivity analyses. In the base case, the primary outcome measure for the cost-effectiveness analysis was change from the baseline score of sexual functioning measured by using standardized results of both the FSFI and IIEF at 6 months, and for the cost-utility analysis, the primary outcome measure was QALY at 6 months based on the SF$6 \mathrm{D}$ using the UK Brazier tariff. Nonparametric bootstrap simulations were used to quantify the uncertainty around the ICERs, yielding information about the joint distribution of cost and effect differences. To determine the cost utility, we used a willingness to pay per QALY of $\$ 1,112$ to $\$ 12,236$. This threshold was calculated with information provided by the Counsil for Public Health and Health Care [Raad voor de Volksgezondheid en Zorg] (2006).

Several sensitivity analyses were performed to test for the robustness of the findings. Except for the first sensitivity analysis (where only study completers were included), all analyses were executed using the base-case data set where missing data were imputed. All analyses used nonparametric bootstrap resampling techniques to explore the uncertainty around estimates of 
cost-effectiveness and cost utility. First, participants who did not miss a single measurement were analyzed (ISH, $n=17$; BSC, $n=19$; NT, $n=19)$. Second, cost-effectiveness was calculated for male and female adolescents separately, because the results could be different when using the original questionnaires and not a standardized version. Third, because the physical components of the SF-36 might not be accurate for adolescents with a sexual dysfunction, cost utility was calculated using only the mental status-related components of the SF-36. Fourth, cost-effectiveness and cost utility were calculated from a health care perspective (i.e., only using the total health care costs in the analyses). Fifth, to account for any baseline differences, both cost-effectiveness and cost-utility analyses were calculated with a correction for baseline differences in costs. For this baseline correction, we used the delta adjustment method (van Asselt et al., 2009). Finally, costeffectiveness was calculated using a longer time horizon of 9 months for the ISH and BSC intervention groups; for the NT group, these data were not available.

\section{RESULTS}

\section{Baseline Characteristics}

The recruitment population consisted of 580 adolescents, and 157 of them participated in the screening. Of these 157 participants, 44 participants were not eligible, mainly due to too high Center for Epidemiological Studies Depression Scale (Bouwma et al., 1995) and Brief Symptom Inventory scores (de Beurs \& Zitman, 2005); 11 were not willing to participate; 30 did not respond to any e-mails; and 1 did not have complaints. Seventy-one adolescents were randomized to ISH $(N=23), \mathrm{BSC}(\mathrm{N}=$ $27)$, or NT $(N=21)$. The study sample consisted of 11 male $(M=21.91, S D=1.97)$ and 60 female $(M=21.72, S D=1.85)$ adolescents with a sexual dysfunction. Every participant that was randomly assigned in the study survived.

In Table 1, baseline characteristics of the three groups are described. There were no differences in demographic (age, gender, relationship status, number of children, education, and employment status) or diagnostic (sexual functioning based on the FSFI and IIEF) baseline characteristics. Furthermore, there were no significant differences in costs between the three treatment groups at the start of the trial.

\section{Costs}

Table 2 presents the volumes of health care use during the 6-month follow-up period for each group. Furthermore, Table 3 presents the uncorrected costs of the different cost items. Costs were bootstrapped and stratified per group. Societal costs were the highest for ISH $(\$ 2,752)$, followed by NT (\$822) and BSC (\$623). The difference between ISH on the one hand and NT and BSC on the other was significant, $U(2)=28.17, p=.001$. Health care costs accounted for $78 \%$ of the total costs. Health care costs and patient and family costs were the highest for ISH (\$2400, \$117), followed by NT (\$344, \$53) and BSC (\$421, \$36). Costs in other sectors were the highest for NT (\$335), followed by ISH (\$234) and BSC (\$166). It can be concluded that the costs for the BSC group were the lowest in every sector.

\section{Effects}

\section{Clinical effectiveness and QALYs}

In the base-case analysis, the results show a mean sexual functioning of -.024 for ISH, .12 for BSC, and .11 for NT. There were no significant group differences, $F(1,70)=1.665, p=$ .20. With respect to male and female adolescents separately, it was found that in male adolescents, both treatment groups (ISH and BSC) had improvement effect sizes that were not expected. Sexual functioning, as measured with the IIEF, was found to be deteriorated after treatment rather than improved. With respect to NT, sexual functioning - counter to expectations-improved. In female adolescents, both treatment groups yielded marginal effect sizes. Sexual functioning, as measured with the FSFI, was found to be improved after treatment. As 
TABLE 1. Baseline Characteristics

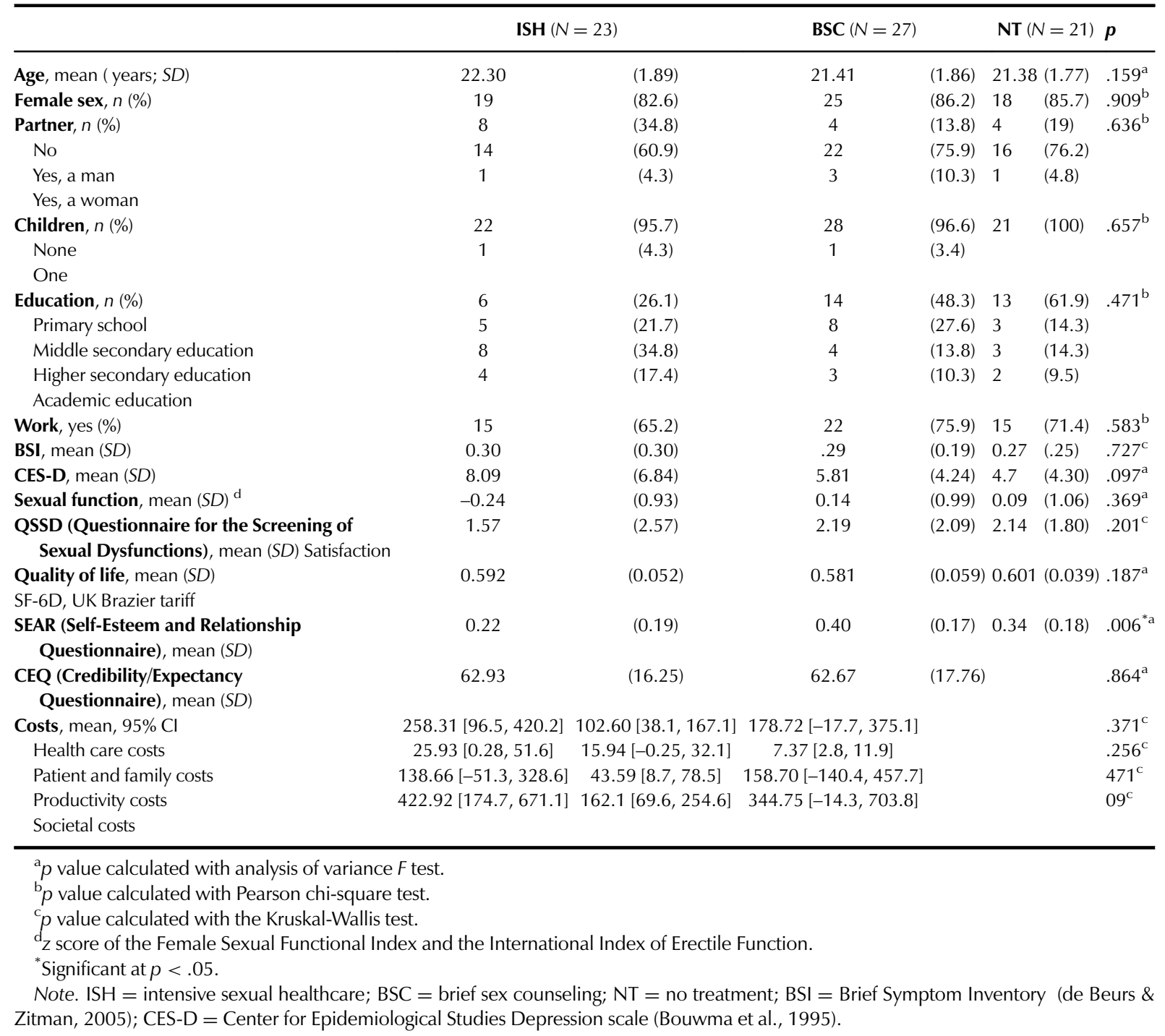

expected, sexual functioning of female adolescents in the NT group further deteriorated.

Furthermore, the results show a mean QALY of .32 for ISH, .31 for BSC, and .31 for NT. There were no significant differences between the groups in QALYs, $F(1,70)=.395$, $p=.68$.

\section{Cost-Effectiveness and Cost Utility}

The costs and level of sexual functioning of BSC versus ISH and BSC versus NT separately are plotted in cost-effectiveness planes (Figure 1a). BSC tends to be more effective and has lower costs than ISH $(90 \%$ of the bootstrapped pairs are lying in the cost-effective southeast quadrant). When looking at BSC versus NT, the majority of the replications (45\%) also lie in the southeast quadrant, thus meaning that BSC is more effective and has lower costs than NT.

With respect to the costs and effects of cost per QALY (Figure 1b), the results show that BSC is more cost-effective than ISH (55\% of the bootstrapped pairs are lying in the cost-effective southeast quadrant). With respect to the comparison between BSC and NT, the results show that the majority of the replications lie in the 
TABLE 2. Volumes of Health Care Use During the 6 Months After Baseline

\begin{tabular}{|c|c|c|c|c|c|c|c|c|c|c|}
\hline \multirow[b]{2}{*}{ Health Care Items (Unit) } & \multicolumn{3}{|c|}{ ISH } & \multicolumn{3}{|c|}{$\mathrm{BSC}$} & \multicolumn{3}{|c|}{ NT } & \multirow[b]{2}{*}{ Source Prices } \\
\hline & Mean $(S D)$ & Max & Med & Mean $(S D)$ & Max & Med & Mean $(S D)$ & Max & Med & \\
\hline Brief sex counseling ( $N$ sessions) & $0.09(0.29)$ & 1 & 0 & $2.18(1.24)$ & 4 & 2 & $0.57(0.98)$ & 3 & 0 & 1 \\
\hline General practitioner ( $N$ consults) & $2.33(2.16)$ & 6 & 2 & $2.15(2.58)$ & 10 & 1 & $2.25(1.89)$ & 6 & 2 & 2 \\
\hline Intensive sexual health care ( $N$ sessions) & $7.65(9.87)$ & 48 & 6 & $0.11(0.42)$ & 2 & 0 & $0.00(0.00)$ & 0 & - & 2 \\
\hline Psychologist ( $N$ sessions) & $0.39(0.89)$ & 3 & 0 & $0.11(0.42)$ & 2 & 0 & $0.15(0.66)$ & 3 & 0 & 2 \\
\hline Other mental health professional ( $N$ consults) & $0.09(0.29)$ & 2 & 0 & $0.07(0.27)$ & 1 & 0 & $0.05(0.22)$ & 1 & 0 & 2 \\
\hline Medical specialist ( $N$ consults) & $1.22(2.75)$ & 10 & 0 & $0.37(0.93)$ & 4 & 0 & $0.86(1.46)$ & 6 & 0 & 2 \\
\hline Company welfare worker ( $N$ consults) & $0.27(1.25)$ & 6 & 0 & $0.11(0.58)$ & 3 & 0 & $0.00(0.00)$ & 0 & - & 3 \\
\hline Social worker ( $N$ sessions) & $0.22(1.05)$ & 5 & 0 & $0.00(0.00)$ & 0 & - & $0.15(0.65)$ & 3 & 0 & 2 \\
\hline Center for Alcohol and Drugs ( $N$ consults) & $0.04(0.21)$ & 1 & 0 & $0.11(0.58)$ & 3 & 0 & $0.00(0.00)$ & 0 & - & 1 \\
\hline Hospital day treatment ( $N$ half days) & $0.22(0.85)$ & 4 & 0 & $0.00(0.00)$ & 0 & 0 & $0.00(0.00)$ & 3 & 0 & 2 \\
\hline Hospital stay ( $N$ days) & $0.13(0.63)$ & 3 & 0 & $0.00(0.00)$ & 0 & - & $0.24(0.89)$ & 0 & 0 & 2 \\
\hline Self-help group ( $N$ sessions) & $0.17(0.38)$ & 1 & 0 & $0.00(0.00)$ & 0 & - & $0.00(0.00)$ & 0 & - & 2 \\
\hline $\begin{array}{l}\text { Prescribed medication, not for } \\
\text { psychological disorders }(€)\end{array}$ & $15.8(40.8)$ & 184 & 0 & $6.5(16.5)$ & 59 & 0 & $36.9(84.9)$ & 368 & 0 & 4 \\
\hline Over-the-counter medication $(€)$ & $3.4(11.28)$ & 47 & 0 & $7.0(16.1)$ & 50 & 0 & $8.9(27.3)$ & 117 & 0 & 4 \\
\hline
\end{tabular}

Note. ISH = intensive sexual health care; BSC = brief sex counseling; NT = no treatment; $a=$ including all forms of general practitioner consults (at the practice, at patient's home, by telephone); $1=$ cost prices according to public health service; $2=$ cost prices according to Dutch standard cost prices of Hakkaart-van Roijen et al. (2010); $3=$ cost prices according to other economic evaluation; $4=$ cost prices according to http://www.medicijnkosten.nl.

southwest quadrant $(47 \%)$, indicating that BSC has lower costs but is also less effective than NT. However, still, $39 \%$ of the replications lie in the dominant (southeast) quadrant.

Furthermore, the base-case cost-effectiveness analysis with the bootstrapped societal costs at 6 months and sexual functioning (standardized values of the FSFI and IIEF) as outcome is presented in Figure 2. BSC has a higher probability of being cost-effective than the other two comparisons (ISH and NT) up to a willingness to pay of $\$ 39,206$, varying from a

TABLE 3. Total Mean Costs in Euros Per Cost Item at 6 Months After Baseline $(N=71)$

\begin{tabular}{lccc}
\hline Cost Type & ISH $(N=23)$ & BSC $(N=27)$ & $N T(N=21)$ \\
\hline Health care costs [95\% CI]* & $2,153[1,508.0,3,068.8]$ & $378[295.3,478.8]$ & $390[203.9,658.7]$ \\
Mental health care & $1,727.05(401.59)$ & $265.71(38.70)$ & $70.96(26.43)$ \\
Intervention & $1,673.12(403.84)$ & $240.81(117.57)$ & $49.03(18.18)$ \\
Other mental health care & $53.93(22.92)$ & $24.90(15.85)$ & $21.93(21.93)$ \\
General practitioner & $81.45(17.04)$ & $61.87(14.05)$ & $65.73(12.87)$ \\
Medical specialist & $91.06(42.43)$ & $30.60(14.65)$ & $68.84(25.37)$ \\
Company welfare worker & $58.55(16.75)$ & $0.00(0.00)$ & $0.00(0.00)$ \\
Social worker & $13.15(13.15)$ & $0.00(0.00)$ & $10.36(10.36)$ \\
Center for Alcohol and Drugs & $3.29(3.29)$ & $8.29(8.29)$ & $0.00(0.00)$ \\
Hospital day treatment & $63.49(51.73)$ & $0.00(0.00)$ & $0.00(0.00)$ \\
Hospital stay & $69.36(69.36)$ & $0.00(0.00)$ & $121.38(98.84)$ \\
Self-help group & $1.90(0.88)$ & $0.00(0.00)$ & $0.00(0.00)$ \\
Medication & $42.06(27.37)$ & $12.95(4.24)$ & $52.93(19.60)$ \\
Patient and family costs [95\% CI]* & $106.3[71.2,148.9]$ & $32.7[17.9,53.8]$ & $47.7[17.1,86.8]$ \\
Traveling & $105.64(19.66)$ & $30.04(8.84)$ & $31.05(13.52)$ \\
Informal care & $0.63(0.63)$ & $2.66(2.66)$ & $16.60(13.51)$ \\
Costs in other sectors [95\% Cl]* & $210.0[52.7,479.1]$ & $149.0[64.4,250.6]$ & $300.8[80.5,649.6]$ \\
Productivity costs & $70.83(29.54)$ & $106.47(44.02)$ & $183.97(77.72)$ \\
Absenteeism from study & $139.12(101.08)$ & $42.49(21.02)$ & $116.86(85.70)$ \\
Societal costs [95\% CI]* & $2469.0[1,750.8,3,410.6]$ & $559.7[418.0,720.5]$ & $738.8[396.6,1,165.6]$ \\
\hline
\end{tabular}

Note. ISH = intensive sexual health care; $\mathrm{BSC}=$ brief sex counseling; NT = no treatment.

*The upper and lower confidence limits are the 2.5 and 97.5 percentile based on 5,000 bootstrap replications. 


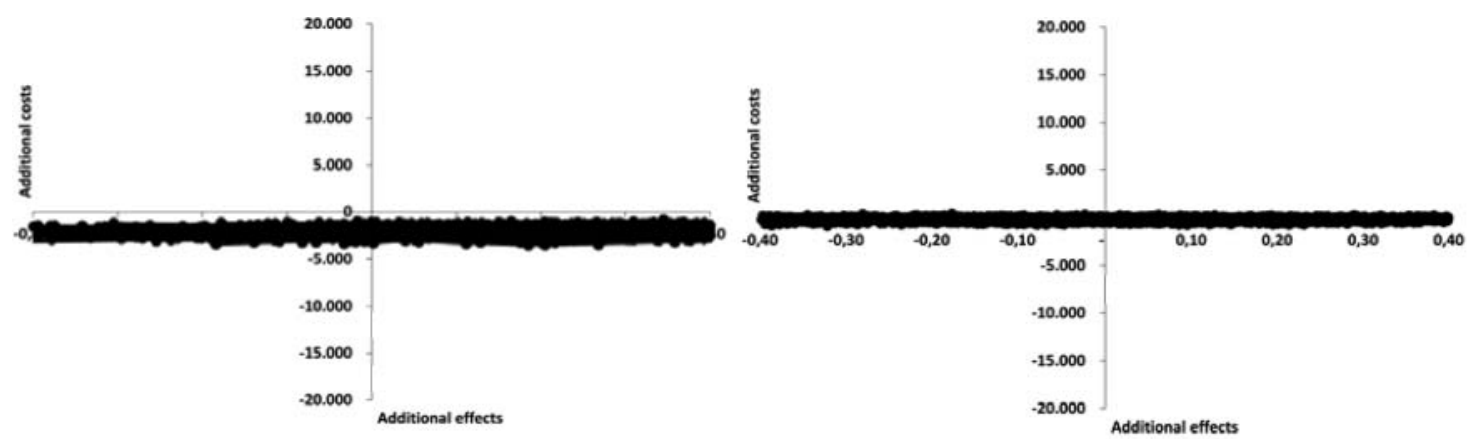

(a)

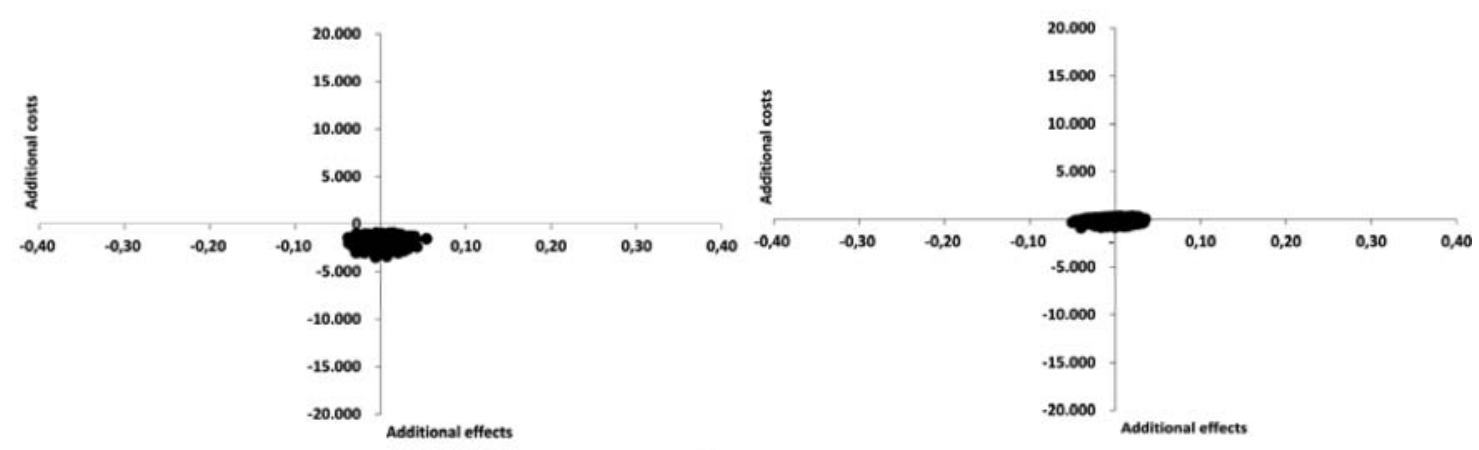

(b)

FIGURE 1. (a) BSC versus ISH—sexual functioning. BSC versus NT—sexual functioning. (b) BSC versus ISH—QALY. BSC versus NT—QALY. Note. ISH = intensive sexual health care; $\mathrm{BSC}=$ brief sex counseling; NT = no treatment; $\mathrm{QALY}=$ quality-adjusted life year.

probability of $79 \%$ at a cost-effectiveness threshold of $\$ 0$ to $34 \%$ at a cost-effectiveness threshold of $\$ 36,238$. When considering the threshold value of $\$ 12,265$, BSC has a probability of $42 \%$ of being the most optimal

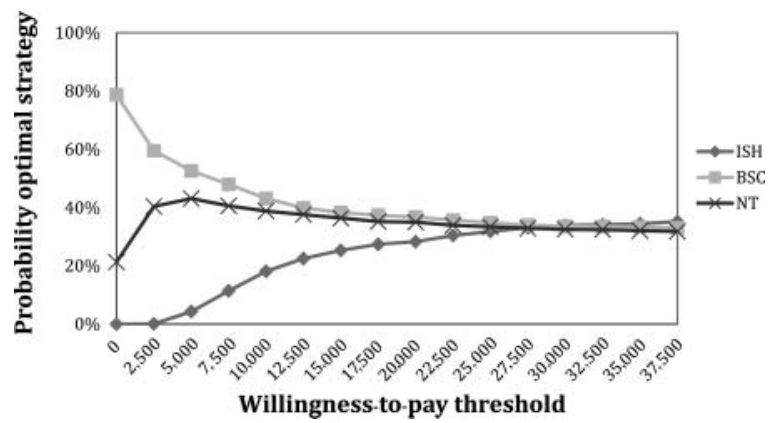

FIGURE 2. Cost-effectiveness acceptability curves looking at sexual functioning at 6 months after baseline Note. ISH = intensive sexual health care; $B S C=$ brief sex counseling; $N T=$ no treatment. treatment option, followed by NT with 38\% and ISH with $20 \%$. It should be noted that the difference between BSC and NT becomes indifferent after this point. The choice between the three study options

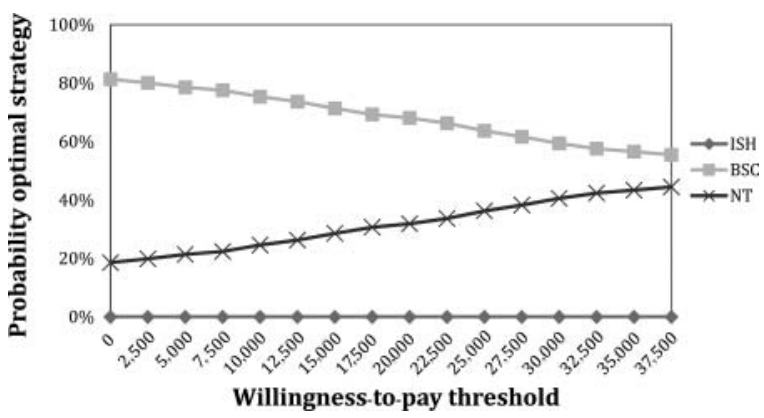

FIGURE 3. Cost-effectiveness acceptability curves looking at quality-adjusted life years at 6 months after baseline. Note. ISH = intensive sexual health care; $\mathrm{BSC}=$ brief sex counseling; $\mathrm{NT}=$ no treatment. 
becomes indifferent, as all curves approach a probability of $33 \%$ when the threshold is higher than $\$ 39,026$.

The base-case cost-utility analysis with the bootstrapped societal costs at 6 months and the SF-6D as outcome is presented in Figure 3. With an $81 \%$ probability of being the most optimal treatment option at a threshold value of $€ 0$ per gained QALY and a probability of $75 \%$ at a threshold value of $\$ 12,265$ per gained QALY, BSC tends to be superior when compared with ISH and NT. The probability of being the most optimal treatment option increases for NT when the willingness to pay increases. However, up to a willingness to pay of $\$ 55,272$ per gained QALY, BSC has the highest probability to be the most optimal treatment option.

\section{Sensitivity Analyses}

\section{1) Study completers only}

In this scenario, data from study completers only were used. Results of the cost-effectiveness analysis (Appendix Figure 1) were comparable to the base-case analysis. Also here, BSC tended to be the most optimal treatment option when compared with ISH and NT; however, the difference between BSC and $\mathrm{ISH}$ is more prominent in favor of BSC. At any threshold, BSC has a higher probability of being cost-effective than the other two comparisons (ISH and NT). Overall, these results support the robustness of the base-case analysis. With respect to the cost-utility analysis (Appendix Figure 2), BSC has the highest probability of being the most optimal treatment option up to a willingness to pay of $\$ 19,513$.

\section{2) Comparison of sexual functioning between male and female adolescents}

In this scenario, sexual functioning was calculated for male (Appendix Figure 3) and female (Appendix Figure 4) adolescents separately. With respect to sexual functioning in female adolescents, the results are comparable with the base-case analysis. BSC is considered to be the best treatment option irrespective of the willingness-to-pay threshold. With respect to sexual functioning in male adolescents, NT is considered to be superior over BSC and ISH. These results indicate that the results of the base-case analysis might be influenced by a gender effect.

\section{3) Mental status-related components of the SF-36}

In this scenario, only the mental properties of the SF-36 (Appendix Figure 5) were used because these aspects are thought to better reflect sexual problems. The results suggest BSC is the most optimal treatment option, up to a willingness to pay of $\$ 19,513$.

\section{4) Analyses based on a health care perspective}

In this scenario only health care costs were included in the analyses. Both cost-effectiveness (Appendix Figure 6) and cost utility (Appendix Figure 7) were comparable to the base-case analyses. However, the difference between BSC and NT is only very limited, suggesting that when only considering health care costs, BSC and NT are comparable treatment strategies.

\section{5) Correction for baseline costs}

In this scenario, the total costs were corrected for differences in baseline costs. Both cost-effectiveness (Appendix Figure 8) and cost utility (Appendix Figure 9) were comparable to the base-case analyses. The difference in costeffectiveness between BSC and NT is only very limited, suggesting that when correcting for baseline costs, BSC and NT are comparable treatment strategies. However, the preference of BSC over NT is more prominent with respect to cost utility.

\section{6) Cost-effectiveness at 9 months}

In this scenario, a 9-month follow-up period (Appendix Figure 10) after baseline was used to compare ISH and BSC. The cost-effectiveness analysis was comparable to the base- 
case analysis. BSC remains the most optimal treatment strategy. These results suggest that the effect remains stable even after a longer followup period.

\section{DISCUSSION}

The aim of the present study was to examine the cost-effectiveness and cost utility of BSC for adolescents with a sexual dysfunction. BSC was compared to ISH and NT. Based on both the cost-effectiveness and cost-utility analyses, BSC is a suitable treatment option for adolescents with a sexual dysfunction.

The results of the cost-effectiveness analysis indicate BSC as the most optimal treatment option, up to a willingness to pay of $\$ 38,992$. Although there were no significant differences in clinical effectiveness between the three groups, results show that in female adolescents, sexual functioning increases for BSC and ISH and decreases for NT. The initial increase in sexual functioning could be explained by the decrease, although not significant, in depressive symptoms and overall psychological problems. The lack of a significant difference in clinical effect indicates that this result is mainly caused by the difference in costs, not by effect.

In the cost-utility analysis, BSC was the most optimal treatment option. When closely looking at the division of costs, it can be concluded that societal costs are significantly higher for ISH than for BSC and NT. Mental health care costs, especially intervention costs, are relatively high in ISH. Furthermore, costs in other sectors were higher for NT, followed by ISH and BSC. The lack of guidance during the waiting period and the fact that their problems were not resolved might cause the higher absenteeism from school and work in this group.

Results of the sensitivity analyses, except for the results of the comparison between male and female adolescents, overall confirmed the robustness of the base-case analyses. The most important difference was the higher probability of BSC to be preferred over ISH and NT when only the data of study completers were analyzed. From a health care perspective and when correcting for baseline costs, the difference in cost-effectiveness between BSC and NT was less prominent. Furthermore, results showed that when using the mental properties of the SF-36 only, the difference between BSC and ISH and NT was less conclusive than when the total SF-36 was used. An explanation for this finding could be that the SF-36 measures both physical aspects and mental aspects and that the mental aspects do not cover only psychological distress. This instrument might be less sensitive and responsive for adolescents with a sexual dysfunction (Wiebe, Guyatt, Weaver, Matijevic, \& Sidwell, 2003). The best solution would be to develop a utility measure that also is suitable for people with sexual dysfunctions. The results of this study point out that a generic utility measure makes it more difficult to examine the cost utility for a specific mental disorder. Furthermore, this indicates that costutility analyses might be less suitable than costeffectiveness analyses for adolescents with a sexual dysfunction due to the lack of a sexual component in the cost-utility analyses.

\section{Methodological Considerations}

Several methodological considerations concerning this study should be taken into account. First of all, this study had to deal with a substantial amount of missing values (32\%). The dropout of participants could be explained by two factors. First, due to the time between the measurements (3 months), it may have been difficult for the participants to remember what had happened during the previous 3 months and because of this they were not motivated to fill in the questionnaires. Furthermore, $65 \%$ of the participants dropped out after their treatment had finished. This finding could indicate that adolescents are motivated to complete questionnaires as long as they might be of interest for the treatment they receive. In adult populations, the dropout after treatment termination is not as high (Bamelis, Evers, Spinhoven, \& Arntz, 2013; de Graaf et al., 2009). This suggests that when including adolescent participants in randomized controlled trials, 
extra incentives should be provided in the follow-up period to ensure that they continue to complete questionnaires.

Second, there was a difference in the procedure of recording the data of the costs between the intervention costs and other costs. All costs were recorded using self-report data from the participants. With respect to intervention costs, we used the data received from the treatment centers yielding the actual number of sessions that the participant received. The number of sessions reported by the treatment centers did not always correspond to the number of treatment sessions reported by the adolescents. It might be possible that the self-reported costs were overestimated or underestimated, and as a consequence, they might have influenced the results.

Furthermore, there is no previous research that has examined the effect of a sexological treatment for adolescents with a sexual dysfunction, and consequently, there are no previous scientific data that provide information about the ceiling value of the willingness to pay. In previous research, various ceiling values per gained QALY have been mentioned and range from values of $\$ 4,010$ to $\$ 164,047$ (Counsel for Public Health and Health Care, 2006; GyrdHansen, 2003; King, Tsevat, Lave, \& Roberts, 2005). Thus, despite the absence of a clear guideline, it can be expected that the used ceiling value of up to $\$ 12,254$ is sufficient.

\section{Conclusion and Recommendations}

To our knowledge, this study is the first that has explored the cost-effectiveness and cost utility of sexological treatment of adolescents with a sexual dysfunction in general, and more specifically, the effect of BSC. The results of both the cost-effectiveness and cost-utility analyses suggest that BSC has the highest probability of being the most optimal treatment option. Despite the lack of a significant clinical difference between BSC on the one hand and ISH and NT on the other, based on the cost-effectiveness and cost utility, BSC might be considered to be a suitable treatment option for adolescents with a sexual dysfunction. However, it should be noted that the cost-effectiveness is due to the difference in costs, not effect. Because the results of a single study are not sufficient, it is advised that researchers further investigate the effect of BSC. Furthermore, the effect of BSC might also be examined in adults with sexual dysfunction.

\section{REFERENCES}

Akre, C., Michaud, P. A., \& Suris, J. C. (2010). ' $I$ 'll look it up on the Web first': Barriers and overcoming barriers to consult for sexual dysfunction among young men. Swiss Medical Weekly, 140, 348-353.

Bakker, F., de Graaf, H., de Haas, S., Kedde, H., Kruijer, H., \& Wijsen, C. (2009). Seksuele gezondheid in Nederland 2009 [Sexual healthcare in the Netherlands 2009]. Utrecht, The Netherlands: Rutgers Nisso Group.

Bakker, F., \& Vanwesenbeeck, I. (2006). Seksuele gezondheid in Nederland 2006 [Sexual healthcare in the Netherlands 2006]. Delft, The Netherlands: Eburon.

Bamelis, L., Evers, S., Spinhoven, P., \& Arntz, A. (2013). Results of a multicentered randomized controlled trial on the clinical effectiveness of schema therapy for personality disorders. Unpublished manuscript.

Bouwma, J., Ranchor, A., Sanderman, R., \& van Sonderen, E. (1995). Het meten van symptomen van depressie met de CES-D: een handleiding [Measuring depressive symptoms with the CES-D: A guideline]. Groningen, The Netherlands: Noordelijk Centrum voor Gezondheidsvraagstukken.

Brazier, J., Roberts, J., \& Deverill, M. (2002). The estimation of a preference-based measure of health from the SF-36. Journal of Health Economics, 21, 271-292.

Burgos, J., Gaebler, J., Strathdee, S., Lozada, R., Staines, H., \& Patterson, T. (2010). Costeffectiveness of an intervention to reduce $\mathrm{HIV} / \mathrm{STI}$ incidence and promote condom use among female sex workers in the Mexico-US border region. PLoS One, 5, e11413.

de Beurs, E., \& Zitman, F. (2005). De Brief Symptom Inventory (BSI). De betrouwbaarheid en validiteit van een handzaam alternatief voor de 
SCL-90 [The Brief Symptom Inventory (BSI). The reliability and validity of a practical alternative for the SCL-90]. Leiden, The Netherlands: Leids Universitair Medisch Centrum.

de Graaf, L., Gerhards, S., Arntz, A., Riper, H., Metsemakers, J., Evers, S., ... Huibers, M. (2009). Clinical effectiveness of online computerised cognitive behavioural therapy without support for depression in primary care: $A$ randomised trial. British Journal of Psychiatry, 195, 73-80.

Drummond, M., Sculpher, M., Torrance, G., O'Brien, B., \& Stoddart, G. (2005). Methods for economic evaluation of health care programmes (3rd ed.). New York, NY: Oxford University Press.

Goldmeier, D., Malik, F., \& Green, J. (2004). Cost implications of sexual dysfunction: The female picture. International Journal of Impotence Research, 16, 130-134.

Grauvogl, A., Evers, S., van den Hoek, K., van der Veen, E., Franke, A., \& van Lankveld, J. (2009). Research into the efficacy and cost-effectiveness of brief, free of charge and anonymous sex counselling to improve (mental) health in youth: Design of a randomised controlled trial. BMC Public Health, 9, 459.

Grauvogl, A., \& van Lankveld, J. (2009). Protocol brief sex counselling. Unpublished manual.

Gyrd-Hansen, D. (2003). Willingness to pay for a QALY. Health Economics, 12, 1049-1060.

Hakkaart-van Roijen, L., Tan, S., \& Bouwmans, C. (2010). Handleiding voor kostenonderzoek: Methoden en standaard kostprijzen voor economische evaluaties in de gezondheidszorg (Geactualiseerde versie 2010) [Dutch manual for costing: Methods and standard costs for economic evaluations in health care (actualized version 2010)]. Diemen, The Netherlands: College voor Zorgverzekeringen.

Hakkaart-van Roijen, L., van Straten, A., Donker, M., \& Tiemens, B. (2002). Trimbos/iMTA Questionnaire for Costs Associated With Psychiatric Illness (TIC-P). Rotterdam, The Netherlands: Erasmus University Rotterdam.

ljff, M. (2006). Sexcounseling. Handleiding voor seksuologische hulpverlening [Sexcounseling: Guidelines for a sexual health professional]. Assen: Van Gorcum.
Kedde, H. (2012). Seksuele disfuncties in Nederland: Prevalentie en samenhangende factoren [Sexual dysfunctions in the Netherlands: Prevalence and involved factors]. Tijdschrift voor Seksuologie, 36, 98-108.

King, J., Tsevat, J., Lave, J., \& Roberts, M. (2005). Willingness to pay for a qualityadjusted life year: Implications for societal health care resource allocation. Medical Decision Making, 25, 667-677.

Koopmanschap, M., Meerding, W., Evers, S., Severens, J., Burdorf, A., \& Brouwer, W. (2004). Handleiding voor het gebruik van PRODISQ. Een modulaire vragenlijst over de relatie tussen ziekte en productiviteitskosten. Toepasbaar bij economische evaluaties van gezondheidszorgprogramma's voor patiënten en werknemers [Guideline for the use of the PRODISQ. A modular questionnaire concerning the relationship between illness and productivity costs. Applicability in economic evaluations]. Rotterdam, The Netherlands: Erasmus Universiteit Rotterdam, Erasmus Medisch Centrum; Maastricht, The Netherlands: Universiteit Maastricht.

Leusink, P., \& Nauta, M. (2009). Seksuele Gezondheidszorg. Deel 2 Handboek Seksualiteit en reproductie [Sexual healthcare. Part 2: Guidelines for sexuality and reproduction]. Bilthoven: RIVM.

Masters, W., \& Johnson, V. (1970). Human sexual response. Boston, MA: Little, Brown.

Prochaska, J. O., \& Velicer, W. F. (1997). The transtheoretical model of health behavior change. American Journal of Health Promotion, 12, 38-48.

Raad voor de Volksgezondheid en Zorg. (2006). Zinnige en duurzame zorg [Sensible and sustainable care]. Den Haag, The Hague: Zoetermeer.

Rosen, R., Brown, C., Heiman, J., Leiblum, S., Meston, C., Shabsigh, R., ... D'Agoostino, R., Jr. (2000). The Female Sexual Function Index (FSFI): A multidimensional self-report instrument for the assessment of female sexual function. Journal of Sex \& Marital Therapy, 26, 191-208.

Rosen, R., Riley, A., Wagner, G., Osterloh, I., Kirkpatrick, J., \& Mishra, A. (1997). The International Index of Erectile Function (IIEF): A 
multidimensional scale for assessment of erectile dysfunction. Urology, 6, 822-830.

Schouten, H. (1995). Adaptive biased urn randomization in small strata. Biometrics, 51, 1529-1535.

van Asselt, A., van Mastrigt, G., Dirksen, C., Arntz, A., Severens, J., \& Kessels, A. (2009). How to deal with cost differences at baseline. Pharmacoeconomics, 27, 519-528.

Vroege, J., Lotgerink, H., van der Rhee, K., Tanis-Nauta, M., \& Weijmar Schultz, W. (2007). Behandeling van seksuele problemen in de eerstelijn, de tweedelijns somatische gezondheidszorg of de tweedelijns GGZ? [Treatment of sexual dysfunctions in medical healthcare or mental healthcare?] Tijdschrift voor Seksuologie, 31, 80-84.

Ware, J., \& Sherbourn, C. (1992). MOS 36-item Short Form Health Survey (MOS-SF-36). Ghent, Belgium: Universiteit Gent.

Wiebe, S., Guyatt, G., Weaver, B., Matijevic, S., \& Sidwell, C. (2003). Comparative responsiveness of generic and specific quality-of-life instruments. Journal of Clinical Epidemiology, $56,52-60$.

Zaric, G., Brandeau, M., Bayoumi, A., \& Owens, D. (1998). The effect of protease inhibitors on the spread of HIV and the development of drug resistance: a simulation study. Simulation, 71, 262-75.

\section{APPENDIX}

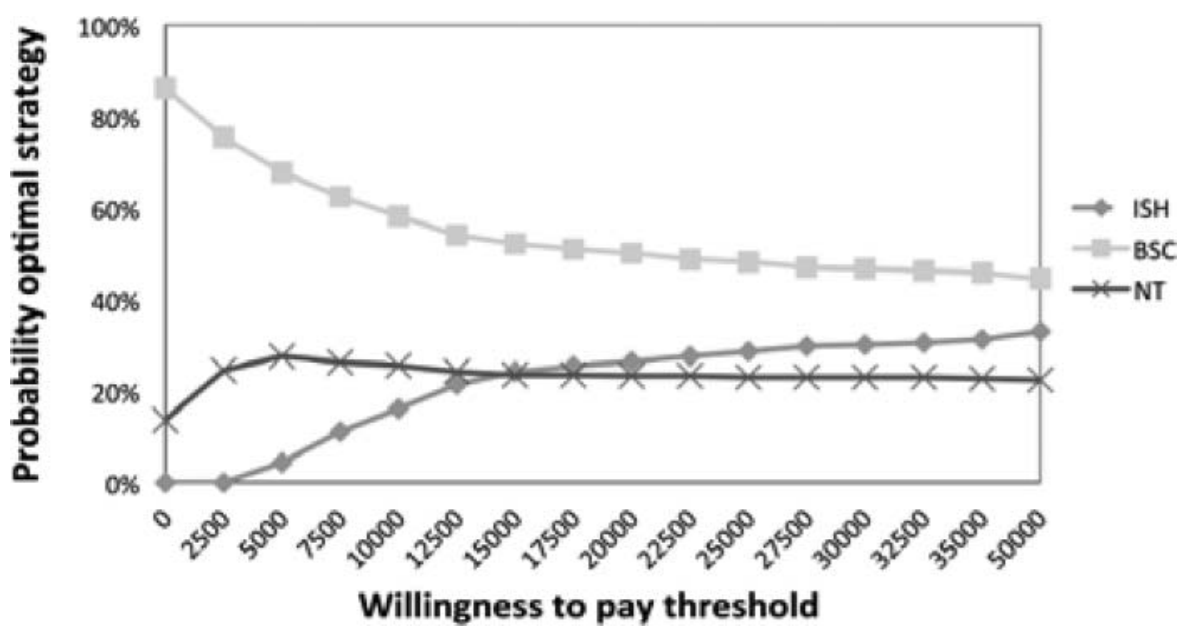

APPENDIX FIGURE 1. Cost-effectiveness, study completers.

Note. $\mathrm{ISH}=$ intensive sexual health care; $\mathrm{BSC}=$ brief sex counseling; $\mathrm{NT}=$ no treatment. 


\section{APPENDIX (Continued)}

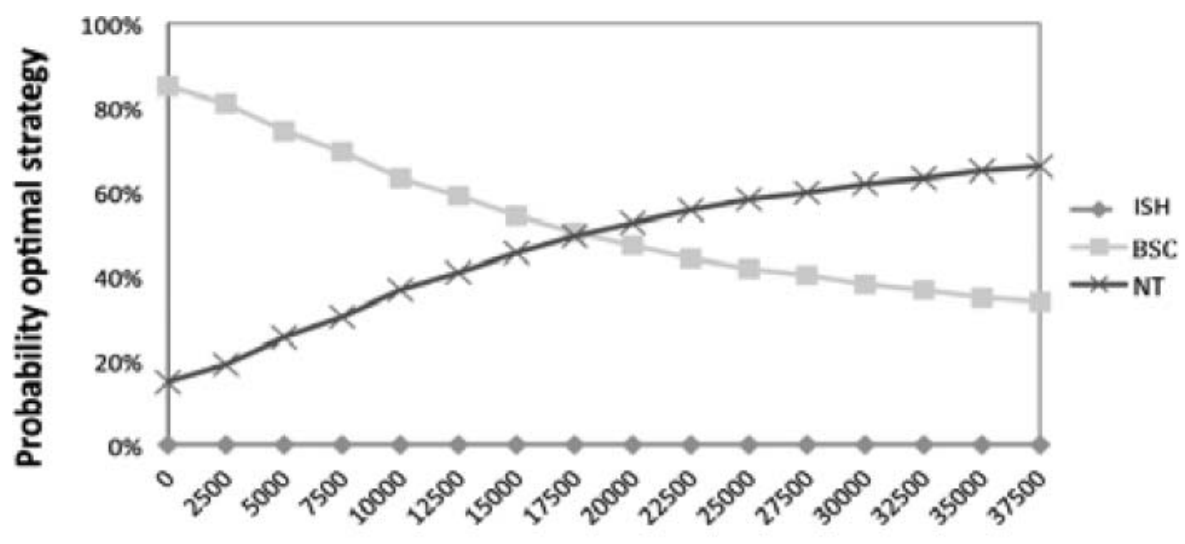

Willingness - to - pay threshold

APPENDIX FIGURE 2. Cost utility, study completers.

Note. ISH = intensive sexual health care; $\mathrm{BSC}=$ brief sex counseling; NT = no treatment.

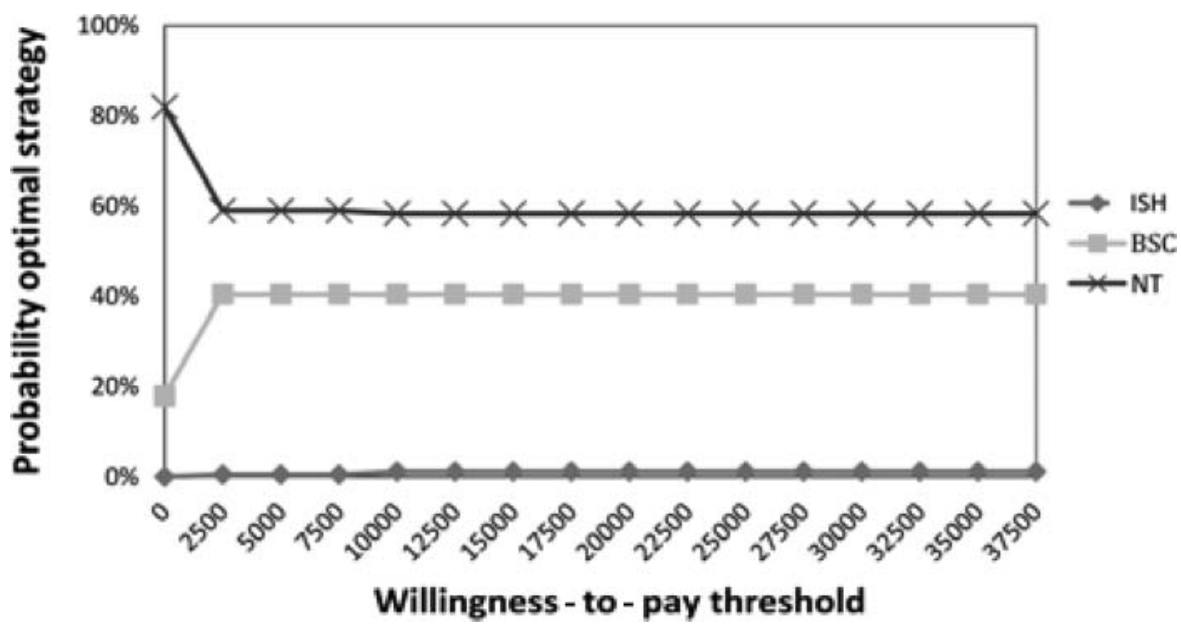

APPENDIX FIGURE 3. Cost-effectiveness, male adolescents.

Note. ISH = intensive sexual health care; $\mathrm{BSC}=$ brief sex counseling; NT = no treatment.

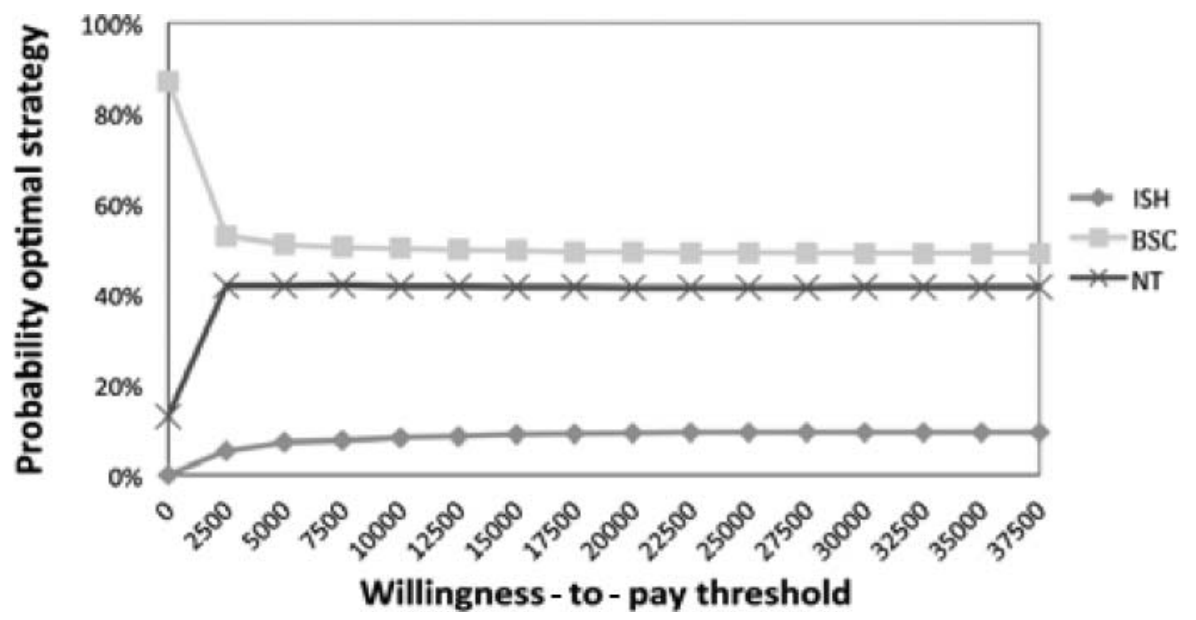

APPENDIX FIGURE 4. Cost-effectiveness, female adolescents.

Note. ISH = intensive sexual health care; $\mathrm{BSC}=$ brief sex counseling; NT = no treatment. 


\section{APPENDIX (Continued)}

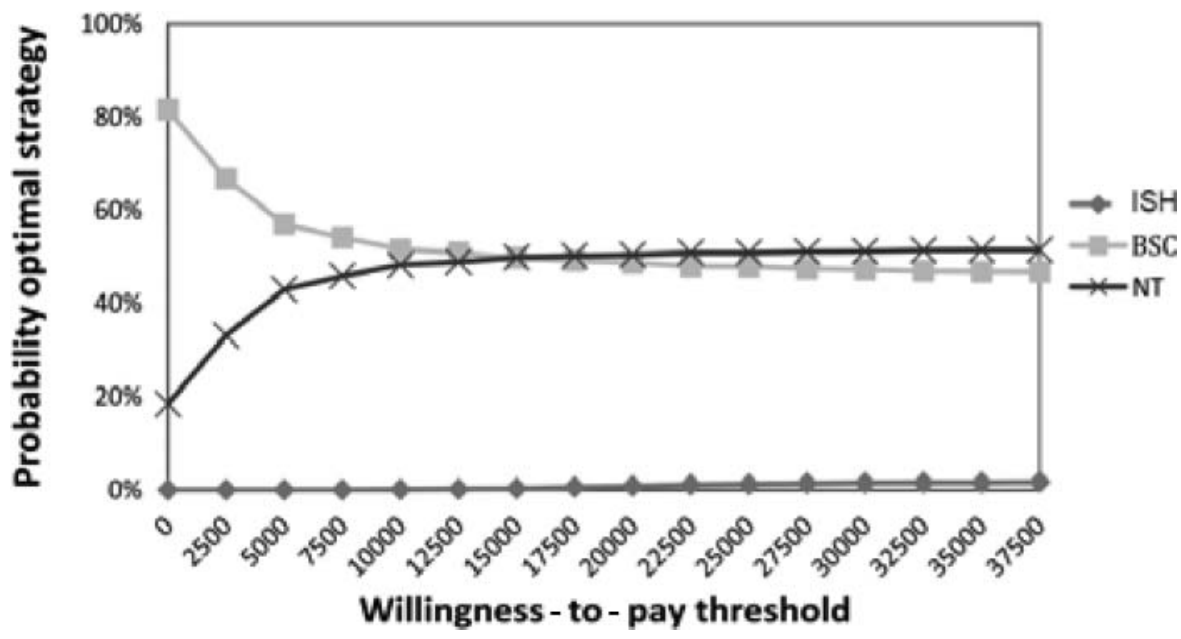

APPENDIX FIGURE 5. SF-36 mental aspects.

Note. ISH = intensive sexual health care; $\mathrm{BSC}=$ brief sex counseling; $\mathrm{NT}=$ no treatment.

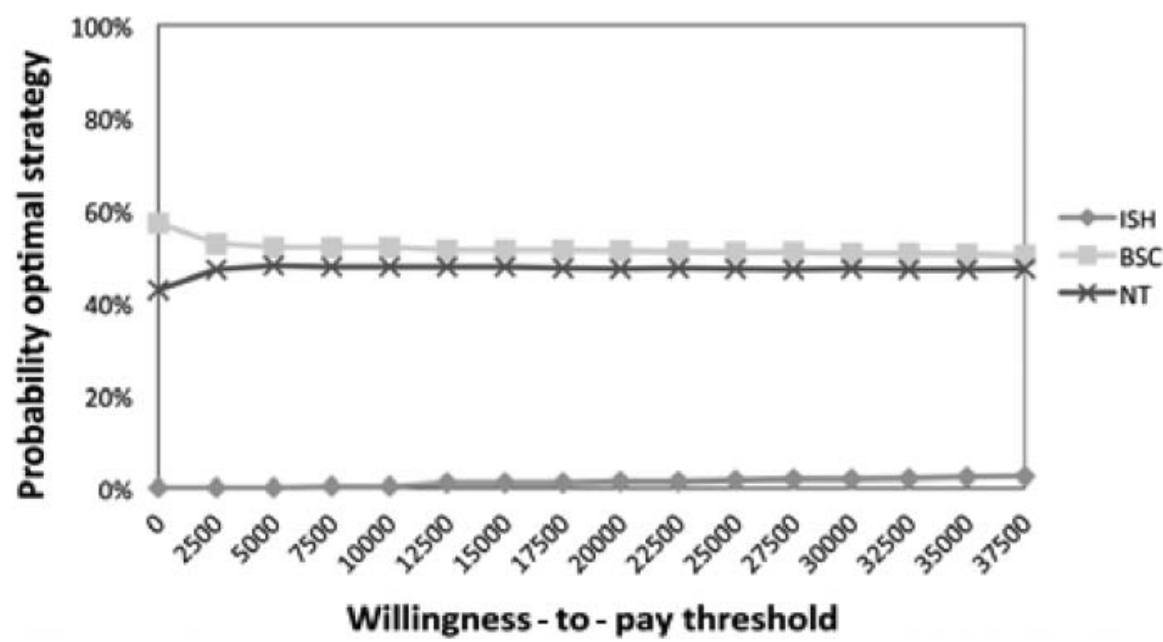

APPENDIX FIGURE 6. Cost-effectiveness, health care perspective.

Note. $\mathrm{ISH}=$ intensive sexual health care; $\mathrm{BSC}=$ brief sex counseling; $\mathrm{NT}=$ no treatment.

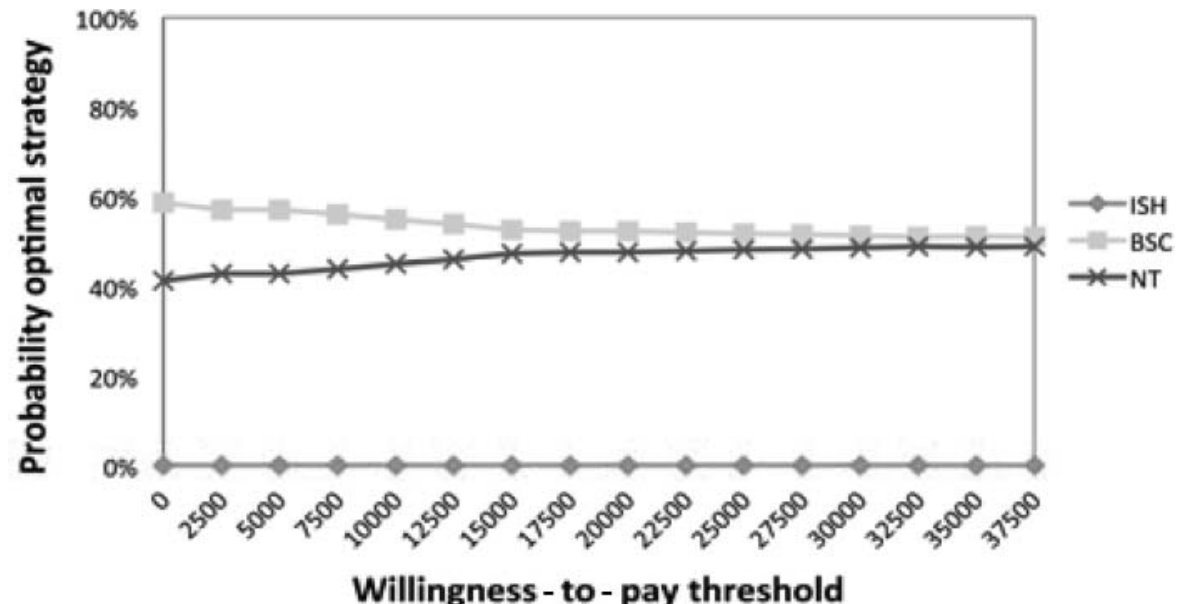

APPENDIX FIGURE 7. Cost utility, health care perspective.

Note. ISH = intensive sexual health care; $\mathrm{BSC}=$ brief sex counseling; $\mathrm{NT}=$ no treatment. 


\section{APPENDIX (Continued)}

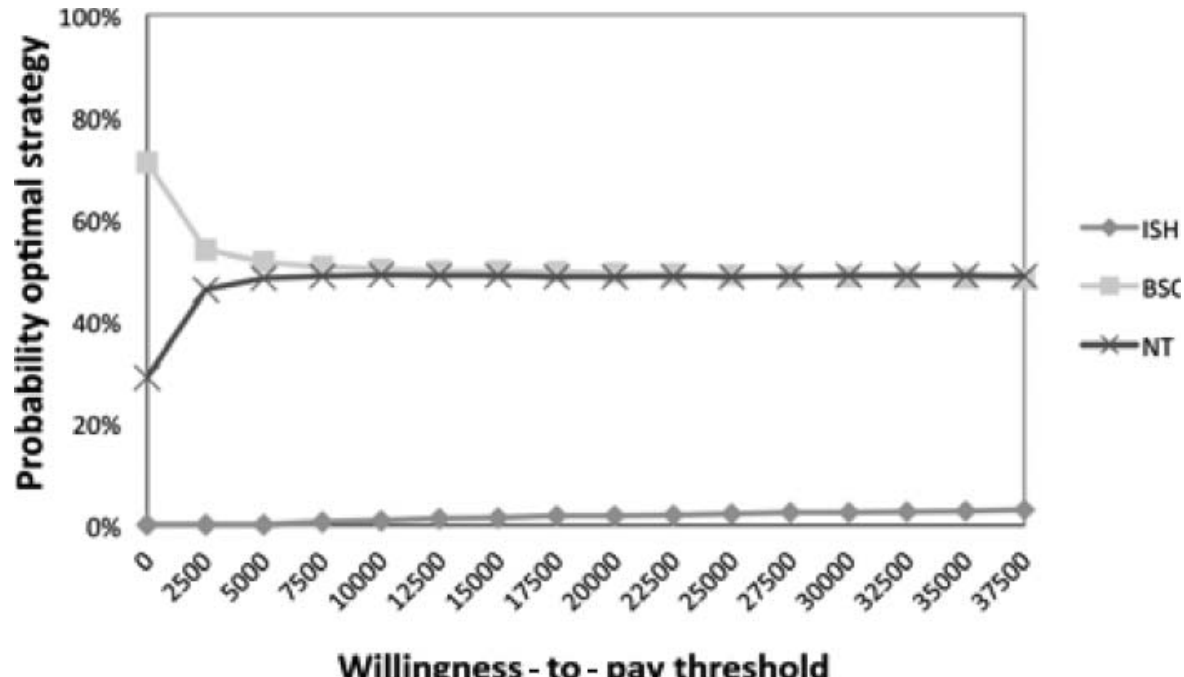

APPENDIX FIGURE 8. Cost-effectiveness correction at baseline.

Note. ISH = intensive sexual health care; $\mathrm{BSC}=$ brief sex counseling; $\mathrm{NT}=$ no treatment.

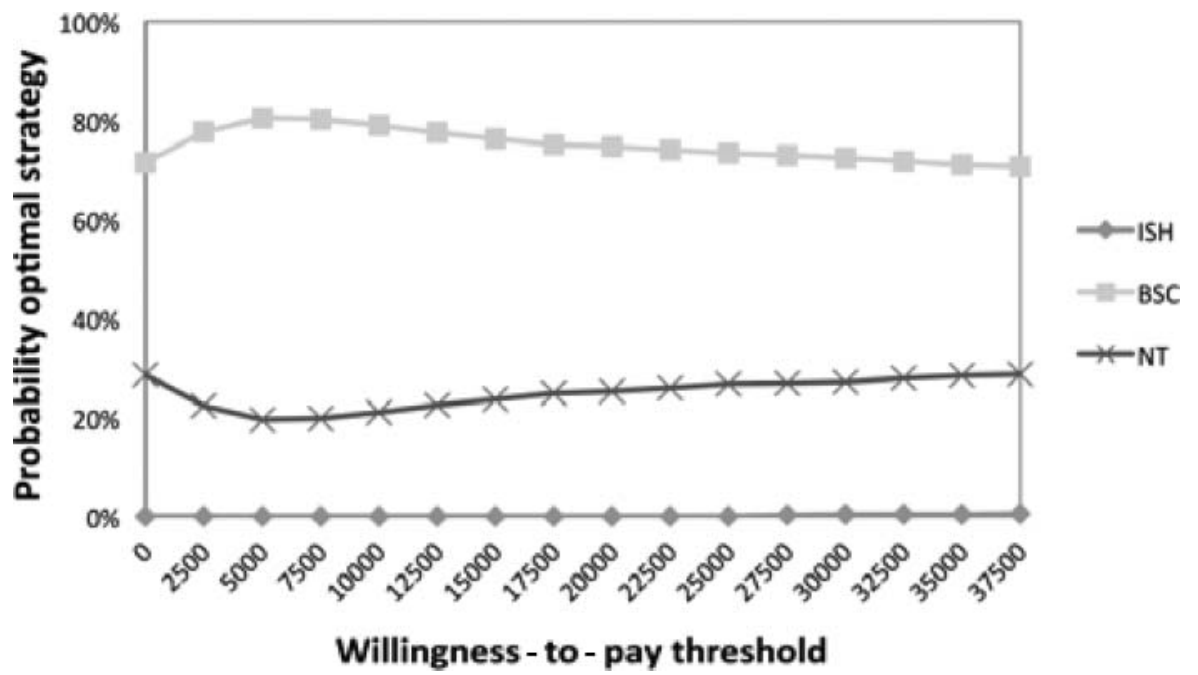

APPENDIX FIGURE 9. Cost utility correction at baseline.

Note. ISH = intensive sexual health care; $\mathrm{BSC}=$ brief sex counseling; $\mathrm{NT}=$ no treatment.

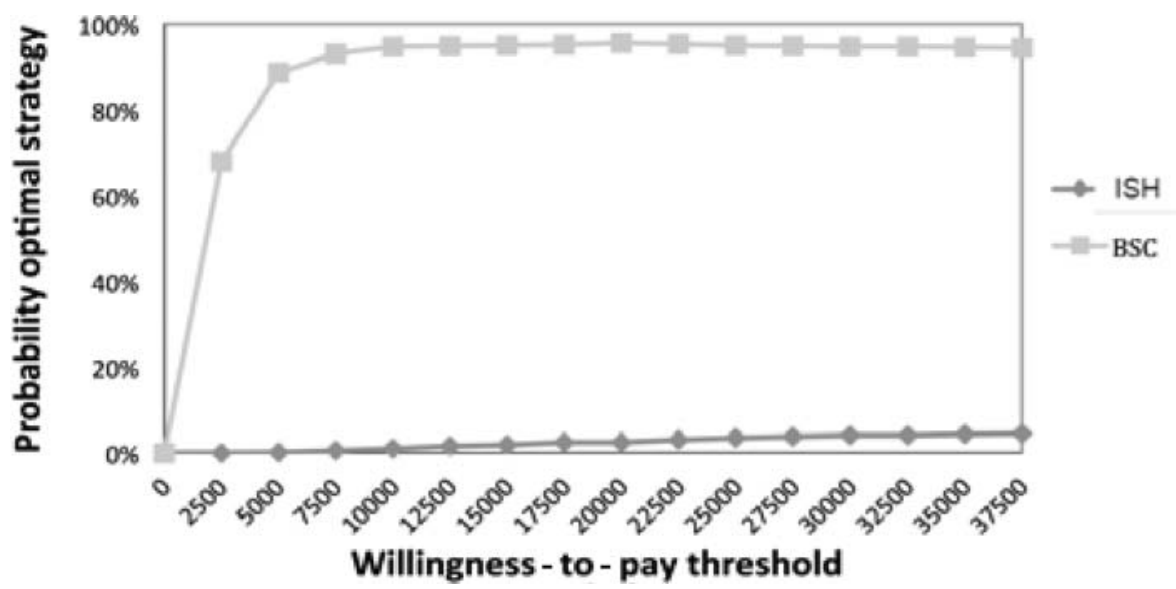

APPENDIX FIGURE 10. Cost-effectiveness at 9-month follow-up.

Note. ISH = intensive sexual health care; $\mathrm{BSC}=$ brief sex counseling; NT = no treatment. 